\title{
INTERCOMPREENSÃO NA ESCRITA DE LÍNGUAS-CULTURAS INDÍGENAS: O CASO DA FAMÍLIA JÊ
}

\author{
Francinete de Jesus Pantoja Pantoja Quaresma ${ }^{1}$ \\ Karina Figueiredo Gaya ${ }^{2}$ \\ Marília de Nazaré de Oliveira Ferreira ${ }^{3}$
}

\begin{abstract}
RESUMO
As comunidades falantes de línguas indígenas, sobreviventes no século XIX, buscam alternativas para a preservação dessas línguas não somente por meio da descrição delas, mas também na educação escolar indígena, com o uso de metodologias de ensino-aprendizagem eficientes que auxiliem a prática do professor indígena na sala de aula. A intercompreensão entre línguas aparentadas é uma metodologia de ensino de língua, aplicada na Europa, cujos resultados satisfatórios levam o aluno estratégias de transferências linguísticas e de autonomia de aprendizado a partir da leitura de textos escritos em línguas pertencentes a uma mesma família, possibilitando ao falante interagir em sua língua materna com falantes de outras línguas. Em meio aos povos indígenas das etnias Parkatêjê, Mẽbẽngôkre e Tapajuna, a intercompreensão pode surgir como uma possibilidade de desenvolvimento do repertório linguageiro de falantes indígenas. Para tanto, faz-se necessário instrumentalizar o professor indígena nessa metodologia, a fim de que ele possa adotá-la em suas aulas de língua indígena. Esse, portanto, é o propósito deste estudo. A teórica que fundamenta este trabalho é pautada na Descrição de Línguas Indígenas e na Linguística Aplicada, sobretudo nos estudos de pesquisadores europeus. Assim, discutimos o assunto a partir de Rodrigues (1993; 1999; 2003), Seki (2000), Cuq (2003), Escudé e Janin (2010), QECR (2001; 2007) e Hugues (2016). A metodologia aplicada para a realização do mesmo foi a pesquisa de cunho bibliográfica.
\end{abstract}

PALAVRAS-CHAVE: Língua indígena. Tronco Macro-Jê. Línguas aparentadas. Intercompreensão entre línguas. Professor indígena.

\begin{abstract}
Bordering on the extinction, Indigenous languages, survivors of the nineteenth century, search for alternatives for their preservation, not only in the description of languages, but also in indigenous school education, through effective teaching-learning methodologies that assist indigenous teacher practice in the classroom. The intercomprehension between related languages is a methodology of language teaching, applied in Europe expounding satisfactory results when developing students' strategies of linguistic transferences and autonomy of learning from the reading of written texts in languages belonging to the same linguistic family, allowing the speaker of one language to establish interaction, in their mother tongue, with speakers of other languages. Among the indigenous people of Parkatêjê, Mẽbẽngôkre and Tapajuna ethnic groups, intercomprehension appears as a possibility for the development of the linguistic repertoire of indigenous speakers. To do so, it is necessary to instrumentalize the indigenous teacher in this methodology, so that he can adopt it in his native language classes. This, therefore, is the purpose of this study. The theoretical basis for this work is

\footnotetext{
${ }^{1}$ Professora vinculada à da Secretaria de Estado de Educação e à Faculdade Teológica Batista Equatorial. Atua com língua portugesa e francesa. Doutoranda em Linguística vinculada ao Programa de Pós-graduação em Letras da Universidade Federal do Pará. Mestre em Linguística pela mesma Universidade (2012). Pesquisadora de língua indígena parkatêjê, na qual desenvolve pesquisa sobre material didático. E-mail: francidejesuspq@yahoo.com.br

2 Professora da Universidade Federal do Pará vinculada à Faculdade de Letras, Campus de Bragança. Doutoranda em Linguística vinculada ao Programa de Pós-graduação em Letras da Universidade Federal do Pará. Mestre em Linguística pela mesma Universidade (2010). E-mail: karinagaya @ gmail.com

${ }^{3}$ Professora Associada III vinculada ao Programa de Pós-graduação em Letras e à Faculdade de Letras da Universidade Federal do Pará. E-mail: mariliaferreira1@gmail.com
} 
based on the Description of Indigenous Languages and Applied Linguistics, especially in the studies of European researchers. Thus, we discuss this issue from the perspective of Rodrigues (1993, 1999, 2003), Seki (2000), Cuq (2003), Escudé and Janin (2010), QECR (2001; 2007) and Hugues (2016). The methodology applied for the accomplishment this study has its ground based upon bibliographical research.

KEYWORDS: Indigenous language. Macro-Jê branch. Related languages. Intercomprehension between languages. Indigenous teacher.

Submetido em: 15.08 .2019

Aprovado em: 27.11.2019

\section{INTRODUÇÃO}

Segundo Seki (2000, p. 246), as línguas indígenas estão fadadas ao desaparecimento. A escrita indígena surge, neste contexto, como uma aliada à preservação das línguas indígenas brasileiras. Contudo, é sabido que a escrita de línguas indígenas não é (ou é pouco) funcional, visto que nenhuma etnia comunica-se entre si, com outro grupo indígena, ou mesmo com a sociedade nacional via modalidade escrita, isto é, faz uso de cartas, documentos, etc. para comunicar.

Não diferente do que ocorre no contexto geral das línguas indígenas, as línguas Parkatêjê, Mẽbẽngôkre e Tapajuna estão ameaçadas de extinção. Diante da situação, a liderança dessas comunidades busca preservar o patrimônio sociocultural e linguístico desses povos. Tais povos indígenas contribuem diretamente com pesquisadores da área da linguística para que suas línguas sejam descritas e, dessa forma, materiais didáticos sejam elaborados a partir das descrições e métodos de ensino de línguas sejam criados e/ou adaptados, a fim de facilitar o processo de ensino-aprendizagem nas escolas indígenas ${ }^{4}$.

No que tange à educação, o ensino de língua indígena precisa ser realizado de forma significativa no meio escolar indígena, de modo a apresentar resultados satisfatórios que contribuam para a retomada das línguas nativas. Os conhecidos métodos de ensino de língua,

\footnotetext{
${ }^{4}$ Parkatêjê: a língua Parkatêjê é falada por uma comunidade indígena que se autodenomina do mesmo modo e que está localizada no sudeste do estado do Pará, no município de Bom Jesus do Tocantins, próximo à Marabá. Atualmente a comunidade é composta por aproximadamente 650 pessoas, segundo o Instituto Socioambiental ISA (2014). A língua Parkatêjê se encontra em perigo de extinção, uma vez que atualmente é falada apenas por um pequeno segmento de sua comunidade, não sendo aprendida mais como primeira língua das crianças, que somente falam o português. Mẽbẽngôkre: são conhecidos como "Gente do buraco d'água" ou "Gente da água grande". Compostos por duas nações indígenas, Kayapó e Xikrin, os Mẽbẽngôkre são considerados o maior grupo Jê com aproximadamente 12.000 pessoas. Habitam as terras do planalto central do Brasil, do estado do Mato Grosso, margeando os rios Araguaia e Curuá ao Pará na foz do rio Xingu. Tapajuna: com população de 132 pessoas (ISA, 2014), autodenominam-se Kajkwakratxi, que significa "tronco do céu", pois esse povo vivia na direção onde fica o sol nascente. Camargo (2015) os apresenta como os "Beiço de pau" devido uso de ornamentos de madeira no lábio inferior. Originalmente estavam localizados às margens do rio Arinos, no estado do Mato Grosso, próximo ao município de Diamantino, e no estado do Pará, onde se encontram no Parque Indígena do Xingu, nas Terras Indígenas Wawi e Capota-Jarina, lar dos Mẽbẽngôkre.
} 
utilizados por muitos educadores no sistema educacional escolar brasileiro e muitas vezes adotados na educação escolar indígena, não são adequados à realidade indígena, cuja cultura deve ser o ponto de partida para qualquer forma de ensino, sobretudo da língua-cultura ${ }^{5}$.

Surgida na Europa, a metodologia da intercompreensão entre línguas aparentadas pode favorecer o ensino-aprendizagem das línguas-culturas indígenas, contribuindo para a funcionalidade da modalidade escrita dessas línguas. Trata-se de uma forma de comunicação na qual cada pessoa se exprime em sua própria língua e compreende a do outro, segundo o Conselho da Europa (2007).

A intercompreensão oral entre línguas indígenas brasileiras é fato quando essas línguas têm a mesma origem, ou melhor, quando são geneticamente aparentadas. Há relatos de que, ao se encontrarem, falantes das línguas Parkatêjê - com outras línguas Timbira -, Mẽbẽngôkre e Tapajuna, por exemplo, pertencentes à mesma família e ao mesmo tronco linguístico, respectivamente Jê e Macro-Jê, comunicam-se perfeitamente, cada etnia usando sua língua materna para interação oral. Contudo, a modalidade escrita, de certa forma, ainda é novidade para alguns povos indígenas. Assim sendo, pode ser possível desenvolver, por meio de uma metodologia apropriada, a compreensão recíproca escrita de falantes de línguas vizinhas a partir do uso que cada um faz de sua própria língua.

Tendo a escrita como uma modalidade a ser ensinada aos povos indígenas Parkatêjê, Mẽbẽngôkre e Tapajuna, pensamos em analisar as referidas línguas a partir do conceito de intercompreensão, a fim de auxiliar não somente os professores indígenas dessas comunidades, mas também os professores indígenas das diferentes etnias que compõem a família Jê, a proporcionar um contato escrito entre povos indígenas de modo multilíngue, bem como aumentar a eficácia da comunicação entre diferentes línguas indígenas.

A intercompreensão de línguas aparentadas é um fenômeno presente na oralidade nas comunidades indígenas em contextos como funeral, festas, visitas em aldeias, reuniões e formação intercultural de professores indígenas, contudo, no que consiste à escrita, ainda precisa ser operacionalizada, tendo em vista que a escrita indígena, por dadas etnias, quase não é utilizada entre si.

\footnotetext{
${ }^{5}$ Compartilhamos o conceito de língua-cultura proposto por Cuq (2003), para quem não é possível dissociar língua e cultura, haja vista que esta está embebida naquela. Para o autor, "do ponto de vista didático, a cultura é o campo de referência que permite ao idioma tornar-se língua: é a função simbólica dessas referências que estabelece a língua como materna, segunda ou estrangeira e que, por consequência, condiciona a função comunicativa." (CUQ, 2003, p.149). O autor argumenta, ainda, que uma língua não serve apenas para comunicação, serve também para identificação, para que os parceiros comunicativos deixem marcas de seu ser e de seus pertencimentos.
} 
Assim sendo, buscamos por meio deste estudo, evidenciar de que forma a metodologia da intercompreensão entre línguas aparentadas pode auxiliar povos indígenas no ensinoaprendizagem das línguas-culturas indígenas. Para tanto, fazemos uma revisão da literatura das línguas indígenas, situando o tronco Macro-Jê e a família Jê dentro do contexto linguístico brasileiro, bem como da literatura sobre intercompreensão entre línguas aparentadas, ideia surgida no início do século XX, na Europa, a fim de apresentar o conceito e as linhas diretivas dessa metodologia; analisamos paradigmas lexicais, morfológicos e sintáticos das línguas Parkatêjê, Mẽbẽngôkre e Tapajuna, evidenciando a possibilidade de intercompreensão entre elas na modalidade escrita; finalizamos propondo uma atividade de instrumentalização das línguas indígenas por meio da metodologia da intercompreensão.

A escolha das línguas Parkatêjê, Mẽbẽngôkre e Tapajuna para realização deste estudo ocorreu devido ao fato de as mesmas serem línguas aparentadas, isto é, pertencentes a mesma família linguística, Jê, e ao mesmo tronco linguístico, Macro-jê, o que possibilita encontrarmos semelhanças quando analisadas em contextos lexicais, morfológicos e sintáticos.

O estudo em questão aponta a semelhança linguística das línguas Parkatêjê, Mẽbẽngôkre e Tapajuna, bem como evidencia que a instrumentalização do método da intercompreensão pode ser favorável ao ensino-aprendizagem das línguas indígenas na modalidade escrita. Dessa forma, a intercompreensão pode valorizar as línguas indígenas na forma escrita face aos seus falantes, vindo facilitar o ensino-aprendizagem dessas línguas nessa modalidade, bem como proporcionar uma comunicação escrita mais justa em contexto intercultural.

A referida pesquisa, de cunho bibliográfico, busca embasamento teórico em autores da literatura da Descrição das Línguas Indígenas Brasileiras e da literatura da Linguística Aplicada Europeia, a saber: Rodrigues (1993; 1999; 2003), Seki (2000), Cuq (2003), Escudé e Janin (2010), QECR (2001; 2007) e Hugues (2016).

\section{AS LÍNGUAS INDÍGENAS BRASILEIRAS}

Segundo Rodrigues (1993), quando os portugueses aportaram nas terras Brasílicas, há mais de 500 anos, falavam-se neste território 1.078 línguas indígenas. Estima-se que atualmente cerca de pouco menos que 200 línguas ainda são faladas no Brasil, 170 delas são autóctones, o que caracteriza este país como sendo plurilíngue, conforme aponta Oliveira (2000). O autor argumenta que somos, portanto, como a maioria dos países do mundo, um país de muitas línguas. 
Rodrigues (2003) corrobora o pensamento de Oliveira (2000), onde afirma que mesmo tendo sido extraordinariamente reduzidas no período da colonização, as línguas indígenas ainda são existentes no território brasileiro e apresentam considerável diversidade, o que caracteriza a Amazônia como sendo, em nível mundial, uma das regiões de maior diferenciação linguística, com mais de 50 famílias linguísticas.

Dessa forma, desmistifica-se a ideia que muitos falantes fazem da geografia linguística das nações: um país, uma língua. Nesse sentido, a língua seria um símbolo constitutivo do Estado. Essa concepção nacionalista, segundo Escudé e Janin (2010), pode ser perigosa não somente para a democracia, mas também para os direitos dos homens, sobretudo dos grupos minoritários, haja vista que a língua é também um instrumento de poder. Assim sendo, a noção do monolinguismo enfraquece as demais línguas que coexistem num dado território, como no caso das línguas indígenas brasileiras.

Num país com dimensões continentais como o Brasil, há pouco ou nenhum interesse em disseminar a ideia do plurilinguismo, de se implantar políticas educativas e programas de aprendizagem para línguas indígenas, uma vez que a realidade plural das línguas é fato comprovado pelas 50 famílias linguísticas outrora mencionadas. A presença dos povos indígenas no Brasil ilustra que não há isolamento linguístico neste território, não somente porque a maioria desses povos fala, além de sua língua materna, a língua portuguesa, mas também porque entre os indígenas pertencentes a uma mesma família linguística há comunicação.

Entende-se por família linguística o agrupamento de línguas em conjunto, realizado por meio de classificação linguística genética. Tal agrupamento estabelece uma hipótese de comum origem dessas línguas no passado, explica Rodrigues (2003). O número de línguas pertencentes à dada família pode variar de muitas dezenas a somente uma e a constituição de uma família com diversas línguas é mais comum, isso implica dizer que no passado houve uma língua ancestral, da qual as atuais línguas constituem modificações diferenciadas, explica o autor. Ainda segundo o autor, mesmo quando se têm estabelecidas diversas famílias linguísticas, podem surgir provas que caracterizem que algumas delas e suas respectivas línguas ancestrais são provenientes de outra língua ancestral ainda mais antiga, formando um conjunto de famílias linguísticas, chamadas de tronco linguístico.

Por meio de estudos descritivos das línguas indígenas brasileiras, segundo Seki (2000), estudiosos conseguiram agrupar dois grandes troncos linguísticos, o Tupi e o MacroJê, e três famílias: aruák, karíb e páno. Nesses troncos são classificadas as famílias linguísticas e suas respectivas línguas. 
Martins et al. (2015) afirmam que a hipótese de um tronco linguístico Macro-Jê teve várias configurações ao longo dos anos, desde sua primeira proposta. A hipótese mais aceitável e confiável pela maioria dos linguistas, conforme os autores, é a de Rodrigues (1999), segunda a qual o tronco Macro-Jê possui 12 prováveis ramos ou famílias linguísticas geneticamente relacionadas, a saber, Jê, Maxakalí, Krenák, Kamakã, Purí, Karirí, Yatê, Karajá, Ofayé, Boróro, Guató, Rikbaktsá. Conforme Rodrigues (2003), pode-se dizer que, contrariamente ao tronco Tupi, o Macro-Jê é tipicamente não amazônico, haja vista que apenas duas das doze famílias nele incluídas possuem línguas na região amazônica: Rikbaktsá e Jê.

Seki (2000) chama atenção para o fato de não se saber ao certo quantas línguas indígenas ainda são faladas no Brasil. A autora afirma que isso ocorre dada às dificuldades de se ter uma definição técnica do que seja uma língua, em relação a dialeto, por exemplo. Moore, Galúcio e Gabas Jr. (2008) afirmam que idiomas considerados diferentes às vezes são apenas dialetos de uma mesma língua, consideradas como tais devido divisões étnicas e políticas. Ainda segundo os autores, geralmente os linguistas usam como critério para agrupar dialetos em línguas a inteligibilidade mútua. Assim, a soma das línguas indígenas existentes no Brasil dificilmente ultrapassa 150 línguas.

Seki (2000, p. 234) afirma que "como qualquer outra das cerca de seis mil línguas naturais existentes, as línguas indígenas são organizadas segundo princípios gerais comuns e constituem manifestações da capacidade humana da linguagem." Cada língua constitui um sistema complexo, com um conjunto específico de sons, categorias e regras de estruturação, sendo, dessa forma, perfeitamente adequada para cumprimento das funções de comunicação, expressão e transmissão, explica a autora.

\section{INTERCOMPREENSÃO ENTRE LÍNGUAS APARENTADAS - CONCEITO E METODOLOGIA}

Conforme Hugues (2016), a intercompreensão vem sendo praticada de modo natural e instintiva pela humanidade há séculos, e vem sendo encorajada e aplicada de modo mais consciente há décadas nos países escandinavos pelas línguas germânicas.

De acordo com o Conselho da Europa, "a intercompreensão é uma forma de comunicação na qual cada pessoa se exprime em sua própria língua e compreende a do outro”. Doué (2005 apud CONSEIL DE L’EUROPE 2007, p. 7) ${ }^{6}$.

\footnotetext{
${ }^{6}$ Tradução das autoras.
} 
Segundo Escudé e Janin (2010), para manter o contato em um meio multilíngue, existe quatro possibilidades: 1) ausência de troca; 2) um dos locutores emprega a língua do outro; 3) os locutores utilizam uma terceira língua para comunicar; 4) os locutores falam cada um em sua própria língua e compreendem a do outro: a intercompreensão. Por meio da abordagem da intercompreensão,

cada um fala ou escreve sua língua e encontra o meio de compreender a língua dos
outros. O único trabalho com a língua efetua-se sobre a atividade de compreensão,
graças à ajuda do contexto, da intencionalidade, da observação das formas. A
produção (fala) efetua-se na língua materna de cada locutor, o que beneficia a
autoridade de cada língua. (ESCUDÉ; JANIN, 2010, p. 28).

Hugues (2016) chama atenção para o fato de a intercompreensão apresentar-se como uma modalidade de comunicação muito antiga em que duas pessoas, ao falarem em línguas diferentes, chegam a se compreender sem que seja necessário passar por uma terceira língua e sem que um precise se expressar na língua do outro, tão antiga que pode ser observada no contexto indígena brasileiro, em especial entre línguas do tronco Macro-Jê, faladas em território amazônico. Segundo o autor, trata-se de uma técnica com bom funcionamento em línguas próximas, isto é, em línguas da mesma família linguística, mas que pode também ocorrer entre locutores de línguas distantes, caso haja treinamento.

Realmente essa não é uma prática nova, em 1913, "Jules Ronjat, fala de intercompreensão para tratar a capacidade de locutores de compreender dialetos de diferentes línguas da mesma família.” (ESCUDÉ; JANIN, 2010, p. 35). Assim, a novidade proposta pelo conceito é sua didatização enquanto teoria e objeto de estudo da Linguística Aplicada. O conceito de intercompreensão entre línguas aparentadas surgiu em 1980, mas veio a ser didatizado no fim do século XX, graças aos estudos desenvolvidos sobre as línguas românicas por Claire-Blanche Benveniste e pelo Conselho da Europa.

Conforme Evenou (2015), os métodos pedagógicos da intercompreensão entre línguas são relativamente recentes ou estão em processo de elaboração. ${ }^{7}$ Enquanto método de ensino de língua,

a intercompreensão toma as famílias de línguas como ponto de partida de sua reflexão sobre a aprendizagem e fundamenta sua didática sob o continuum que elas constituem. A partir de sua língua, o aprendiz vai em direção à compreensão das línguas que lhes são aparentadas. Utiliza-se para isso as transparências lexicais e sintáticas, bem como uma série de traços comuns à família, já que a diversidade de

\footnotetext{
${ }^{7}$ Benveniste (1997) informa que o método da intercompreensão das línguas românicas seria publicado na forma de um volume impresso, acompanhado de DC-Rom, no ano de 1997, pela Editora Nova Itália, em Florença.
} 
cada uma nada mais é do que a declinação singular de traços comuns. (ESCUDÉ; JANIN, 2010, p. 18-19).

Aprender uma língua por meio da metodologia da intercompreensão não significa, primeiramente, aprender novas palavras, uma gramática nova, etc., tal como é proposto nos métodos tradicionais, significa "desenvolver a capacidade de descobrir correspondências entre as línguas familiarizadas no nível fonético, fonológico, ortográfico, vocabular, morfossintático, etc.” (Meissner, 2009, p.2) .

Tais metodologias buscam diminuir consideravelmente o número de esquemas linguísticos para levar o aluno a aprender um número reduzido de regras de correspondência e de estratégias que lhe auxiliarão a explorar uma língua. Nesse sentido, os saberes do aluno são ativados, possibilitando relacionar ou efetuar transferências. Em outras palavras, os sujeitos são incitados a apoiarem-se em suas competências tanto culturais, quanto linguísticas.

Conforme Meissner (2009), a didática da intercompreensão tem se mostrado uma ferramenta muito eficaz para desenvolver capacidades metacognitivas. Tal desenvolvimento ocorre de modo progressivo.

Para Evenou (2015), quando utilizada como abordagem didática, a intercompreensão favorece não somente o desenvolvimento das competências metalinguísticas, mas também a autonomia do aprendiz. Assim, ao se interessar pelo funcionamento do sistema linguístico de dada língua, o aprendiz cria pontes entre tal sistema e aquele já conhecido por ele, utilizandose da estratégia da inferência, vindo, assim, a adquirir mais autonomia em sua aprendizagem e a desenvolver sua capacidade de dedução.

Ao relacionar o que aprendeu com o que já conhece, o aluno reforça a confiança em si mesmo, além de apropriar-se do seu processo de aprendizagem. Um dos objetivos desta metodologia é levar o aluno a ter consciência de sua capacidade plurilíngue. O professor, nesta abordagem de ensino, é um colaborador, o que significa que ele deve dominar a metodologia da intercompreensão, mas não necessariamente precisa dominar o conjunto dos dados linguísticos, gramaticais e fonológicos, do grupo de línguas que estão em contato. Segundo Escudé e Janin (2010), seu papel é monitorar e guiar as hipóteses dos alunos, fornecendo-lhes informações que lhes permitam avançar em sua compreensão e corrigindo as hipóteses falsas levantadas pelo grupo.

Seu papel é apresentar as estratégias de compreensão, contudo não deve se mostrar como o detentor do saber linguístico da língua estudada pelos alunos, pois, na sala de aula, o

\footnotetext{
${ }^{8}$ Tradução das autoras.
} 
professor deve ser colaborativo para a autonomia do aprendiz. O método oferece várias possibilidades para o público visado, de acordo com Escudé e Janin (2010). Esse pode ser formado por crianças ou adultos, em aprendizagem individual ou em grupo.

Conforme Evenou (2015), a didática da intercompreensão faz uso de diferentes métodos de aprendizagem, conforme o público visado, a distância entre as línguas ensinadas e o suporte utilizado. A metodologia pode ser usada tanto para o ensino da modalidade oral, quanto da modalidade escrita. Contudo, é na escrita que a metodologia da intercompreensão encontra sua principal aliada operacional. O grupo de estudo de Benveniste, um dos principais nesta abordagem, pautou sua metodologia apenas em atividades de recepção escrita, isto é, leitura.

Segundo Escudé e Janin (2010), a intercompreensão visa fornecer mecanismos específicos de aprendizagem em dada modalidade para se aprender uma língua, colaborando para que se possa aprendê-la completamente, em todas as dimensões da recepção e da produção de modo eficaz. Como a metodologia proposta por Benveniste privilegia a competência da recepção escrita, ao progredir no aprendizado de uma habilidade, no caso a leitura, o aprendiz acaba progredindo em outras habilidades, a saber: escuta, fala e escrita.

Conforme os autores, há métodos de intercompreensão que se apoiam na escrita da língua auxiliada pelas ferramentas de registros orais. Nas etapas de aquisição e autonomização do aprendiz, a estabilidade da escrita reforça a confiança e assegura ao aluno a construção de estratégias de inferência. A oralidade surge como uma ajuda e como uma necessidade para abordar as línguas na plenitude de suas atividades.

Os pesquisadores que abordam tanto a oralidade quanto a escrita, por sua vez, buscam desenvolver dois domínios em sua abordagem: um consiste em desenvolver a competência de escuta à extensão da competência de leitura; outro em permitir a passagem, por meio da mesma metodologia, a outras famílias de línguas além da família a qual pertence a língua do aprendiz. Percebemos que no primeiro domínio busca-se passar da competência da recepção para a competência da produção; no segundo domínio, visa-se estender a competência da compreensão.

Ainda segundo a Evenou (2015), na aprendizagem de competências receptivas de outras línguas, faz-se necessário considerar a língua materna do aprendiz, a fim de que esse possa ler as línguas pertencentes a sua família linguística. Trata-se de decifrar o texto, fazendo uso de competências de recepção, e não de produção. $\mathrm{O}$ aluno aprenderá a ler as outras línguas pertencentes à família linguística de sua língua materna por um método essencialmente fundado na contextualização e na apropriação dos textos a serem 
compreendidos, esses textos a serem compreendidos, por sua vez, são ditos autênticos, o que estimula a aprendizagem.

Em sua abordagem, os métodos da intercompreensão proporcionam ao aprendiz a consciência de que existe um continuum linguístico que lhe permitirá adentrar nas línguas, seja por meio de sua língua materna, seja por meio de várias línguas pontes. Conforme Escudé e Janin (2010), a maioria dos métodos de intercompreensão parte da aprendizagem simultânea de várias línguas, a fim de explicitar suas semelhanças.

Em síntese, Escudé e Janin (2010) apresentam três objetivos que marcam os métodos de intercompreensão. Assim, a metodologia: a) possibilita a compreensão de enunciados em uma língua-alvo; b) possibilita a aquisição de uma competência metalinguageira, transponível para o maior número de enunciados em línguas desconhecidas; c) encoraja o aprendiz, uma vez assegurado pelo domínio das habilidades de recepção, a adquirir mais habilidades globais em dada língua que ele desejará ou precisará saber.

Hugues (2016) afirma que, na Europa, a intercompreensão foi pensada como uma possibilidade para salvar línguas em vista de desaparecimento, como o patois, por exemplo. Trazendo a abordagem para o contexto brasileiro em que muitas línguas indígenas estão em constante perigo de extinção, a intercompreensão, a nosso ver, pode sim ser pensada como uma alternativa, ainda que com ressalvas, de modo a aumentar a qualidade da intercompreensão nesses idiomas na modalidade escrita. E, ainda, ao permitir a expressão do outro em sua própria língua, a intercompreensão favorece a valorização de dada língua face aos seus próprios falantes, uma vez que a língua constitui um dos traços identitários mais importantes de uma comunidade cultura.

Outros aspectos da abordagem reforçam nosso pensamento. A intercompreensão, por estar integrada à abordagem plurilinguística e pluricultural das línguas, tende a valorizar línguas minoritárias, colocando-as em pé de igualdade a outros idiomas tidos como superiores, pois, conforme afirmam Escudé e Janin (2010), a intercompreensão é um convite para escutar o outro no sentido duplo do termo: literal e moral, em que, linguisticamente, elimina-se qualquer possibilidade de se estabelecer hierarquia entre as línguas, eticamente, coloca-se as língua em igualdade, de modo que haja respeito mútuo nas formas de se expressarem.

Os estudiosos lamentam o fato de tal abordagem ainda estar longe das práticas de ensino-aprendizagem de línguas ocidentais, visto que, para eles, essa é a mais equilibrada e a mais justa dentre as existentes. Se está longe das línguas ocidentais, quiçá das indígenas. Tal pensamento é corroborado com o que afirma Huges (2016), para quem a intercompreensão 
tem uma face profundamente humanista, visto que constitui uma abordagem não somente igualitária, mas também equitativa e aplicável a todos.

\title{
3 INTERCOMPREENSÃO - O CASO DA FAMÍLIA JÊ
}

Rodrigues (1999 apud MARTINS et al. 2015, p. 118-119) apontou a família linguística Jê como a maior família do tronco Macro-Jê e a dividiu em quatro subgrupos, de acordo com sua distribuição regional:

\begin{abstract}
O primeiro subgrupo (atualmente extinto), situado no nordeste do Brasil, é formado pela língua Jaikó, que era falada possivelmente no sudeste do Piauí.

O segundo subgrupo, os Jê do norte, é constituído por cinco línguas: a primeira é a língua Timbíra e seus dialetos falados nos estados do Maranhão, Pará, Tocantins (Canela, Ramkokamekrá, Canela Apanyekrá, Gavião Pykobjê, Gavião Parakatejê, Krinkatí, Krahô, Krênje), totalizando 2.800 falantes; a segunda língua é o Apinajé, falada no norte do Tocantins e possui cerca de 720 falantes; a terceira é o Kayapó, juntamente com suas variações dialetais (Kiretum, Kokraimôro, Kubenkrakén, Menkrangnotí, Mentuktíre, Xikrín), as quais são faladas na parte oriental (lado oeste) do Mato Grosso e sudeste do Pará, com aproximadamente 5.000 falantes; a quarta língua considerada nesse ramo é o Panará, cujos falantes, cerca de 160, estão distribuídos na área indígena do Panará, no norte do Mato Grosso e no sudoeste do estado do Pará; a quinta e última língua desse subgrupo é o Suyá, cujo povo situa-se no Parque Indígena do Xingu, no Mato Grosso, sendo que 213 falam Suyá e 58 falam Tapayuna, variação dialetal da língua Suyá.

O terceiro subgrupo, constituídos dos Jê centrais, constitui-se de quatro línguas, sendo duas extintas e duas vivas. Extintas estão o Xakriabá e o Akroá: esta se situava em Minas Gerais, e aquela na parte oriental de Goiás e sul do Maranhão. Vivas estão o Xerénte e o Xavánte: esta é falada no sudeste de Mato Grosso e possui cerca de 9.000 falantes, e aquela, o Xerénte, com aproximadamente 1.550, é falada em Tocantins.

As línguas que representam o quinto grupo da família Jê situam-se no Sudeste do Brasil: o Kaingáng, o Xokléng e o Ingaín (esta, atualmente morta). O Kaingáng é falado em São Paulo, Paraná e Santa Catarina por aproximadamente 20.000 falantes; e o Xokléng é falado em Santa Catarina por cerca de 1.650 pessoas. (grifos das autoras).
\end{abstract}

As línguas Timbíra (Parkatêjê), Apinajé, Kayapó (Mẽbẽgokrê), Panará e Suyá (Tapajuna), pertencem ao ramo setrentrional da família Jê, do tronco Macro-Jê, um tronco tipicamente não amazônico, segundo Rodrigues (2012). Essas línguas e seus respectivos dialetos apresentam semelhanças em vários aspectos, dentre os quais podemos citar: os de cunho fonético-fonológico, cujas vogais se sobrepõem às consoantes; os de cunho morfológico, em que apresenta a flexão indicadora de contiguidade ou não de um determinante a um determinado, bem como apresenta prefixos relacionais; os de cunho sintático, cuja apresentação da ordem do constituinte em oração declarativa é a mesma, bem como apresenta a ocorrência de verbos em posição final da sentença.

As semelhanças já evidenciadas por meio da descrição dessas línguas indígenas corroboram com o exposto por Escudé e Janin (2010) ao tratarem da unidade (invariante) e 
variedade das línguas. Pautados nos princípios fundamentais dos contatos de línguas, os autores argumentam que as línguas, em toda sua diversidade, possuem estruturas lógicosemânticas universais. Assim sendo, de acordo com a lei da fusão, os autores (2010, p. 36) afirmam que não há isolamento linguístico, isto é, "uma língua nem sempre é absolutamente opaca para outra", portanto, "a opacidade absoluta de um texto não pode existir", sobretudo se as línguas pertencem à mesma família linguística, tal como é o caso das línguas Parkatêjê, Mẽbẽngôkre e Tapajuna.

Contudo, ainda pautados em outra lei fundamental de contato de línguas, a lei da difração, os autores também afirmam que uma língua pode ser infinitamente declinada, isto é, uma língua pode variar em função de mudanças geográficas, sociais, entre outros fatores. Entretanto, o fracionamento linguístico absoluto não pode existir: a língua, tão dialética que seja, continua sendo a declinação de uma matriz linguística comum, isto é, possui uma base semelhante. Cada uma delas constitui-se, portanto, línguas, mesmo possuindo similaridades devido sua língua mãe.

Em relação às referidas línguas indígenas mencionadas neste estudo, tal fato pode ser fundamentado no exposto pelos indígenas Parkatêjê, Mẽbẽngôkre e Tapajuna, quando os falantes dessas línguas admitem que a semelhança entre elas é muito grande, contudo, enfatizam que são línguas distintas. Falantes dessas etnias compreendem-se oralmente, cada um comunicando em sua língua materna.

Em outras palavras, a intercompreensão no nível oral é fato, no nível escrito, por sua vez, precisa ser evidenciado e, consequentemente, instrumentalizado para que o professor tenha consciência de que se trata de uma prática a ser valorizada em seu meio profissional. A intercompreensão entre línguas indígenas na modalidade escrita já é um exercício realizado em sala de aula nas escolas indígenas, ainda que involuntariamente. A título de comprovação da intercompreensão escrita entre etnias indígenas da família Jê, citamos o fato de algumas escolas indígenas fazerem uso de material didático produzido por outra etnia, em sua referida língua. Os Parkatêjê, por exemplo, utilizam-se de livros didáticos elaborados pelos Mẽbẽngôkre.

Para instrumentalização da intercompreensão na modalidade escrita, Escudé e Janin (2010) consideram necessária uma aprendizagem do código para que um falante possa adentrar no universo linguístico de uma língua aparentada, sua porosidade permitirá ao falante compreendê-la. Acreditamos que a metodologia da intercompreensão entre línguas aparentadas pode potencializar a compreensão das referidas línguas indígenas, entre as etnias citadas, na modalidade escrita. 


\subsection{OS PARADIGMAS LEXICAIS, MORFOLÓGICOS E SINTÁTICOS COMUNS EM LÍNGUAS DA FAMÍLIA JÊ}

As línguas Parkatêjê, Mẽbẽngôkre e Tapajuna compartilham a mesma família, a Jê, cujos princípios as levam a partilhar todas as características que as tornam inteligíveis entre si. Por causa dessas semelhanças, essas línguas partilham também suas formas de representação da língua.

A fim de evidenciar o fenômeno da intercompreensão na família linguística Jê, apresentamos dados linguísticos de ordem lexical, morfológica e sintática. O material linguístico utilizado como amostra para a realização deste estudo foi retirado de dicionários das línguas Parkatêjê, Mẽbẽngôkre e Tapajuna, de modo a formar paradigmas lexicais, morfológicos e sintáticos para observamos as semelhanças nas línguas. Para tanto, decidimos selecionar substantivos das referidas línguas como, por exemplo, os que nomeiam animais, partes do corpo humano e objetos do cotidiano indígena, bem como decidimos analisar frases interrogativas, afirmativas e negativas nas línguas para compor o corpus de análise. ${ }^{9} \mathrm{~A}$ amostra analisada é, portanto, composta de fontes secundárias, isto é, o material coletado foi primeiramente utilizado por pesquisadores da linguística descritiva em seus trabalhos de campo para fins de descrição das referidas línguas em diferentes aspectos linguísticos.

Nosso propósito é evidenciar as semelhanças entre as línguas aparentadas a partir dos paradigmas lexicais, morfológicos e sintáticos. Acreditamos que a partir dessa observação os falantes podem ser conscientizados que tais línguas são variantes de uma mesma família, isto é, são dialetos de uma mesma língua, segundo Escudé e Janin (2010), o que, por sua vez, pode proporcionar melhor compreensão entre falantes dessas línguas, sobretudo na modalidade escrita, quando se intercomunicarem cada um em seu idioma.

Quadro 1 - Nomes de animais

\begin{tabular}{|c|c|c|c|}
\hline PARKATÊJÊ & MẼBẼNGÔKRE & TAPAJUNA & PORTUGUÊS \\
\hline Hàk & Àkĩnhàtire & Tàktxi & Gavião \\
\hline Hàkati & Kangãti & Kangãtxi & Jiboia \\
\hline Kire & Ropre & Roptaka & Cachorro \\
\hline $\mathrm{Kra}$ & Ngra & Kra & Paca \\
\hline Mĩre & Mĩ & Mì & Jacaré \\
\hline
\end{tabular}

Fonte: Elaborado pelas autoras

\footnotetext{
${ }^{9}$ A ideia desses paradigmas surgiu a partir da experiência realizada por Escudé e Janin (2010), os quais observaram as semelhanças das línguas românicas a partir do título da obra de Antoine de Saint-Exupéry, O Pequeno Príncipe, escrito em 101 línguas pertencentes a essa família. Assim como os autores, nós não nos deteremos em apontar elementos mórficos que constituem dada palavra exemplificada.
} 
Quadro 2 - Nomes de partes do corpo

\begin{tabular}{|c|c|c|c|}
\hline PARKATÊJÊ & MẼBẼNGÔKRE & TAPAJUNA & PORTUGUÊS \\
\hline Itik & Tik & I'thu & Barriga \\
\hline Hõto & Oto & Tõto & Língua \\
\hline Amahi & Ama & Tama & Queixo \\
\hline Hapak/Apak & Amak & Awàknikãj & Orelha \\
\hline Kà & Kà & Ikà & Pele \\
\hline
\end{tabular}

Fonte: Elaborado pelas autoras

Quadro 3 - Substantivos comuns

\begin{tabular}{|c|c|c|c|}
\hline PARKATÊEJ $\hat{E}$ & MẼBẼNGÔKRE & TAPAJUNA & PORTUGUÊS \\
\hline Aikre & Kikre & Thikhre & Casa \\
\hline Hapakakre & Kre' & Tambakhrekhre & Buraco na orelha \\
\hline Hy & 'y & Ty & Semente \\
\hline Kô & Ngô & Ngô & Água \\
\hline Aikapàt & Akamàt & Akambat & Noite \\
\hline
\end{tabular}

Fonte: Elaborado pelas autoras

Quadro 4 - Sintagmas

\begin{tabular}{|c|c|c|c|}
\hline PARKATÊJÊ & MẼBẼNGÔKRE & TAPAJUNA & PORTUGUÊS \\
\hline Mã pia iji kute? & Mỳj nã anhidji kute? & Myj na anhĩdzi kute? & Como é teu nome? \\
\hline зũm pia iji apãn? & Djãm amã kôr? & Awãw ra kwê nhūm na. & Quem é o teu pai? \\
\hline Wa ita kini nõre. & Imã já kĩnh kêt. & Iwã já kĩ kere. & Eu não gosto disto. \\
\hline Wa kukrē prãmãre. & Ba inhõ kwỳ krè. & Wa inhõ kukhrẽ. & Eu quero comer. \\
\hline Ry mu tē. & Arỳm ne mã tè & Ahry nẽ wã tẽ. & Ele já foi embora. \\
\hline
\end{tabular}

Fonte: Elaborado pelas autoras

\section{PERSPECTIVA}

Entendemos que a instrumentalização da metodologia da intercompreensão de línguas aparentadas entre os professores indígenas das etnias Mẽbẽngôkre, Parkatêjê e Tapajuna pode ser um passo positivo rumo ao ensino-aprendizagem da modalidade escrita dessas línguas indígenas e uma forma de potencializar a compreensão entre povos indígenas nessa modalidade e, quiçá, entre índios e não índios, colaborando, dessa forma, para o rompimento da ideia do monolinguísmo linguístico no Brasil. 
A fim de colaborar para com as pesquisas em línguas indígenas, bem como para com o processo de ensino-aprendizagem dessas línguas, elaboramos uma atividade pedagógica a ser aplicada em cursos de formação de professores indígenas ou em reuniões culturais de etnias da família Jê, na qual os fundamentos teóricos da intercompreensão servem de base para auxiliar o ensino da compreensão escrita de línguas indígenas da família linguística Jê. Tal atividade tem, inicialmente, como público-alvo professores indígenas das etnias Mẽbẽngôkre, Parkatêjê e Tapajuna, podendo posteriormente estender-se às línguas das etnias Apinayé e Paraná, também pertencentes ao ramo setentrional da família Jê.

Nosso objetivo com a atividade pedagógica consiste em apresentar os benefícios da abordagem da intercompreensão entre línguas aparentadas, de modo que os professores indígenas percebam que tal abordagem pode vir a ser benéfica em suas atividades em sala de aula, aumentando a qualidade da intercompreensão entre povos indígenas da família Jê.

Partimos do pressuposto que a comunicação escrita por meio da abordagem da intercompreensão é possível nesta família linguística, haja vista que essa já ocorre por meio da modalidade oral. Conforme relatam indígenas e pesquisadores que atuam entre esses povos, em meio às reuniões culturais ou outros eventos em que diferentes etnias encontramse, como a formação de professores indígenas, por exemplo, cada povo comunica-se em sua própria língua, fazendo-se compreender.

A seguir, descreveremos as etapas a serem desenvolvidas na atividade, vale ressaltar que, durante as mesmas, a língua veicular será a língua portuguesa:

1 - Proporemos aos professores a produção textual de um mito indígena, mais especificamente o mito da criação. A escolha desse gênero textual é justificada pelo fato de os mitos indígenas assemelharem-se, assim entendemos que basicamente teremos as mesmas informações em três línguas diferentes. O texto será produzido em equipe, segundo cada etnia;

2 - Posteriormente pediremos às equipes que troquem o texto produzido para que os próprios membros observem as semelhanças nas produções realizadas em outra língua pertencente a mesma família linguística da sua. O objetivo consiste em levá-los a perceber autonomamente as regularidades dessas línguas;

3 - Após o primeiro olhar do professor no texto escrito pelo colega da outra etnia, proporemos a leitura em voz alta por um dos produtores do texto, pois acreditamos que a oralidade, neste momento, será uma ferramenta de ajuda para a compreensão do texto escrito;

4 - Após, convidaremos os professores a formarem três grupos mesclados, isto é, que contenham professor das diferentes etnias para destacarem as regularidades. A proposta é 
verificar como cada grupo indígena apresentaria dada informação em sua língua, para isso, farão uso de quadros a serem preenchidos ${ }^{10}$;

5 - Na sequência, os grupos farão a exposição oral de seus achados;

6 - Por fim, faremos a culminância das observações, evidenciando as similaridades lexicais, morfológicas e sintáticas das línguas na escrita.

Ressaltamos que a atividade proposta consiste em uma tarefa de intercompreensão voltada especificamente para instrumentalizar o professor indígena, de modo a levá-lo a observar as semelhanças nas línguas familiares e verificar que a metodologia pode ser aplicável em contexto indígena. Assim sendo, prezamos em destacar aspectos da língua a partir dos paradigmas morfológicos, lexicais e sintáticos, tais como fizeram Escudé e Janin (2010) em sua experiência com 101 línguas românicas.

Em suas diretrizes metodológicas, a intercompreensão visa construir no aluno uma gramática da compreensão a partir de pontos de convergência translinguísticos, chamados regras de passagem, haja vista que se trata de um convite a levar o aluno a passar de uma língua para outra por meio do continuum, isto é, proximidade linguística. A atividade proposta possibilitará tal passagem, evidenciando suas similaridades ao criar as pontes entre as línguas vizinhas, provocando o reflexo de previsibilidade na língua, tal como sugere a metodologia em questão.

De acordo com Escudé e Janin (2010), as diversas estratégias da intercompreensão visam levar o aluno a ter consciência de suas potencialidades plurilíngues e lhes dar instrumentos para realizá-las autonomamente, convidando o aluno a apoiar-se em suas competências linguísticas e culturais para compreender o texto.

Entendemos que o registro oral das línguas-alvos desta atividade colaborará grandemente para que o lido seja compreendido em excelência. Por isso propomos a leitura em voz alta das produções dos mitos. Ao realizarmos atividades como estas que propomos, acreditamos estar contribuindo para o desenvolvimento do repertório linguageiro do indígena, conforme apresenta QECR (2001) em relação às línguas europeias.

\section{CONCLUSÃO}

A intercompreensão consiste na aprendizagem de várias línguas dentro da mesma família linguística, estabelecendo igualdade entre elas. Dessa forma, acreditamos que tal

\footnotetext{
${ }^{10}$ Os quadros aqui mencionados referem-se aos apresentados na sessão 4 deste trabalho.
} 
abordagem pode ser vantajosa para as línguas indígenas, principalmente se o professor indígena for instrumentalizado para adotá-la em sua prática docente.

Ao perceber a possibilidade de intercompreensão em sua língua, o professor indígena pode dispor dessa estratégia para melhor conduzir sua prática docente, incentivando, enquanto mediador, os alunos a desenvolverem habilidades em sua língua-cultura indígena.

A proposta da aplicação da metodologia da intercompreensão foi lançada em contexto indígena brasileiro a partir das etnias Mẽbẽngôkre, Parkatêjê e Tapajuna, por meio da atividade pedagógica de instrumentalização do professor à metodologia da intercompreensão descrita na sessão 5 deste estudo. Em virtude de contextos culturais étnicos indígenas, que demandam aos povos originários, por exemplo, a guarda do luto de seus membros falecidos por longo período de tempo, a aplicação da atividade pedagógica não pode ser realizada, conforme estava prevista.

Num período de um ano, o povo Parkatêjê sofreu a perda de dois integrantes de sua liderança: Raimundo, falecido em março de 2018, e Manoel, falecido em janeiro de 2019, situações que restringem a realização de atividades propostas por pessoas externas a sua comunidade. O povo Parkatêjê, de acordo com sua cultura ancestral, deve guardar o luto de seus membros falecidos. Diante do contexto de luto que os Parkatêjê se encontram, cabe a nós, pesquisadores e estudiosos dessa língua indígena, respeitar as tradições e o sentimento de perda desse povo, deixando para momentos posteriores a aplicação da atividade outrora proposta.

A atividade de instrumentalização do professor sugerida para o contexto da educação escolar indígena é apenas o pontapé inicial para divulgação desta metodologia humanística entre povos de línguas minoritárias. Se partirmos do ponto em que o professor é influenciado pela sua própria experiência, o professor indígena agrega às suas aulas a um arcabouço de experiências interculturais e plurilíngue que talvez nunca tenha sido levada em conta por ele ou usada em sala, com a finalidade de expandir a qualidade da intercompreensão.

Devemos levar em conta que por mais que existam fatores políticos, sociais, étnicos e culturais que podem vir a delongar o uso da abordagem da intercompreensão em si, no que se refere à modalidade escrita, o uso dela na modalidade oral já é uma realidade entre povos indígenas.

\section{REFERÊNCIAS}

ARAÚJO, Leopoldina. Dicionário Parkatêjê - Português. Belém: Editora da Autora, 2016. 
BENVENISTE, Claire-Blanche. Questions et réponses. In: BENVENISTE, Claire- Blanche; VALLI, André. Le Français dans le monde - rechercher et applications -

L'intercompréhension: le cas des langues romanes. Paris: Hachette Edicef, 1997, p. 153159.

CAMARGO, Nayara da Silva. Tapayuna (Jê): aspectos morfossintáticos, históricos e sociolinguísticos. 2005. Tese (Doutorado em Linguística) - Departamento de Linguística, Universidade de Campinas, Campinas, 2005.

CONSEIL DE L'EUROPE. De la diversité linguisthique à l'éducation plurilíngue: guide pour l'élaboration des politiques linguistique en Europe. Strasbourg: Conseil de l'Europe, 2007.

CONSEIL DE L'EUROPE. Cadre européen commun de réference pour les langues. Paris: Conseil de l'Europe, Ed. Didier, 2001.

CUQ, Jean-Pierre. Dictionnaire de didactique du français - Langue étrangère et seconde. Paris: CLÉ International, 2003.

ESCUDÉ, Pierre; JANIN, Pierre. Le point sur - l'intercompréhension, clé du plurilinguisme. CLE international, 2010.

EVENOU, Gaid. L’intercompréhension. $2^{\mathrm{a}}$ ed. Paris: Délégation Générale à la langue française et aux langues de France - Réferences, 2015.

FERREIRA, Marília de Nazaré de Oliveira; CAMARGO, Nayara da Silva. Dicionário Eletrônico Tapajuna - Português, 2009.

HUGUES, Sheeren. L'intercompréhension: un nouveau souffle pour les langues romanes minoritaires et pour les dialectes?. Lengas Revue de sociolinguistique [En Ligne], 2016. Disponível em: http://lengas.revues.org/1060;DOI:10.4000/lengas.1060. Acesso em: 10 maio 2017.

INSTITUTO SOCIOAMBIENTAL. Povo Tapajuna. 2014. Disponível em: https://pib.socioambiental.org/pt/Povo:Tapayuna. Acesso em: 20 ago. 2018.

JÕPAIPAIRE, Toprãmre Krôhôkrenhũm. Mẽ ikwỳ tekjê ri: isto pertence ao meu povo. Marabá, PA: Gknoronha, 2011.

MARTINS, Andérbio Márcio Silva et al. O tronco Macro-Jê: hipóteses e contribuições de Aryon Dall'Igna Rodrigues. Revista Fragmentum: revista do Programa de Pós-Graduação em Letras da UFSM, Rio Grande do Sul, n. 46, jul.- dez. 2015. Disponível em: https://periodicos.ufsm.br/fragmentum/article/view/23392.

MEISSNER, Franz-Joseph. Pourquoi l'intercompréhension romane intéresse-t-elle les non-romanophones? Conséquences pratiques etétat de lieux en matière des recherches germanophones. Barcelona, 2009. Disponível em: https://www.unigiessen.de/fbz/fb05/romanistik/didaktik/Team/prof/emeritus/meissner/off/externeveranstaltungen/dateien/Meissner_T_Ronde. Acesso em: 21 ago. 2018. 
MOORE, D. A.; GALÚCIO, A. V.; GABAS, Jr. N., 2008. O desafio de documentar e preservar línguas amazônicas. Scientific American Brasil. Amazônia: Destinos, vol 3. Disponível em: http://etnolinguistica.wdfiles.com/local-files/media\%3Aset2008/moore_2008_desafio.pdf.

OLIVEIRA, Gilvan Müller. Brasileiro fala português: monolinguísmo e preconceito linguístico. In: MOURA e SILVA (Org.). $O$ direito à fala - a questão do preconceito linguístico. Florianópolis, Editora Insular, 2000.

RODRIGUES, Aryon Dall'Igna. Línguas Indígenas. 500 anos de descobertas e perdas. Ciência e Cultura, 1993, p. 20-26.

RODRIGUES, Aryon Dall'Igna. Macro-Jê. In: DIXON, R. M. W.; AIKHENVALD, A. Y. The Amazonian languages. Cambridge: Cambridge University Press, 1999, p.164-206.

RODRIGUES, Aryon Dall'Igna. Aspecto da história das línguas indígenas da Amazônia. In: SIMÕES, M. S. Sob o signo do Xingu. Belém: Ed. da UFPA, 2003, p. 37-51.

RODRIGUES, Aryon Dall'Igna. Flexão relacional no tronco Macro-Jê. Revista Brasileira de Linguística Antropológica do Instituto de Letras da UNB, Brasília, n. 2, dez. 2012.

Disponível em: http://periodicos.unb.br/index.php/ling/article/view/20691. Acesso em: 16 maio 2018.

SEKI, Lucy. Línguas Indígenas do Brasil no Limiar do Século XXI. Impulso, 2000, p. 233 256. Disponível em: http://unimep.br/phpg/editora/revistaspdf/imp.27art11.pdf. Acesso em: 16 maio 2018.

TRAPP, Roy. Um vocabulário pequeno da língua Kayapó. Missão Cristã Evangélica (MICEB), 1996. 